\title{
Modification of expanded polytetrafluoroethylene valved conduit using the thin-type leaflets
}

\author{
Yusuke Yamamoto, MD, ${ }^{\mathrm{a}}$ Masaaki Yamagishi, MD, PhD, ${ }^{\mathrm{b}}$ Takako Miyazaki, MD, PhD, ${ }^{\mathrm{b}}$ \\ Satoshi Asada, MD, ${ }^{\mathrm{b}}$ Yoshinobu Maeda, MD ${ }^{\mathrm{b}}$ Hitoshi Yaku, MD, PhD,${ }^{\mathrm{c}}$ and Hideaki Kado, $\mathrm{MD}^{\mathrm{d}}$
}

\section{ABSTRACT}

Objectives: The expanded polytetrafluoroethylene conduit with fan-shaped leaflets and bulging sinuses for right ventricular outflow tract reconstruction was modified with a newly developed thin-type expanded polytetrafluoroethylene leaflet. The purpose of this study was to evaluate the clinical outcomes and hemodynamic performance of the modified conduit.

Methods: From January 2010 to December 2013, 149 patients underwent definitive right ventricular outflow tract reconstruction using the expanded polytetrafluoroethylene conduit; the 55 patients receiving a conventional conduit (group $\mathrm{N}$ ) were compared with the 94 patients receiving a modified conduit (group T).

Results: There were no conduit-related deaths, operative deaths, or reimplantations for conduit failure. The overall survival and freedom from reintervention for conduit-related reasons at 3 years were $98.2 \%$ versus $95.6 \%(P=.438)$ and $94.7 \%$ versus $97.9 \%(P=.954)$ for groups $\mathrm{N}$ and $\mathrm{T}$, respectively. The mean peak pressure gradients were $22.6 \pm 15.6 \mathrm{~mm} \mathrm{Hg}$ versus $18.2 \pm 11.5 \mathrm{~mm} \mathrm{Hg}(P=.161)$, and in the subanalysis within small-sized conduits, they were $30.2 \pm 16.5 \mathrm{~mm} \mathrm{Hg}$ versus $20.4 \pm 10.7 \mathrm{~mm} \mathrm{Hg}(P=.034)$. Regarding conduit insufficiency, the modified conduit showed a significantly worse grade of insufficiency $(P=.014)$ only in the subanalysis within largesized conduits.

Conclusions: Although the clinical outcomes did not differ within midterm observation, the thin-type expanded polytetrafluoroethylene leaflet was considered to be suitable for the small-sized conduits, but not for large-sized conduits, based on the comparison of the hemodynamic performance. Long-term followup is necessary to address the appropriate sheet type for middle-sized conduits and to estimate the durability of the thin-type leaflet. ( $\mathrm{J}$ Thorac Cardiovasc Surg 2018;156:1629-36)

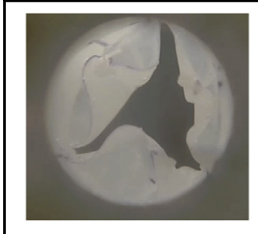

Normal leaflet

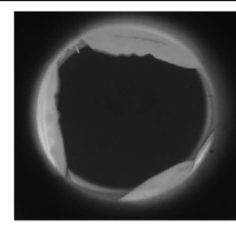

Thin-type leaflet
Comparison of maximum valve opening between the 2 types of leaflets.

\section{Central Message}

The thin-type ePTFE sheet as a leaflet materia of the ePTFE valved conduit provides reduction of pressure gradient in the small-sized conduit, but increased regurgitation in the large-sized conduit.

\section{Perspective}

In the midterm observation, clinical outcomes of the 2 types of ePTFE conduits were equivalent regardless of the significant difference of hemodynamic performance. Further follow-up study will reveal the chronologic changes of the thin-type leaflets and the significance of this modification on the clinical outcomes in the long-term, and it will help improvement of the ePTFE conduit.

See Editorial Commentary page 1637
Although several materials are used as an artificial valve in right ventricular outflow tract (RVOT) reconstruction for congenital heart disease, no material is ideal in terms of availability, hemodynamic performance, and, in particular,

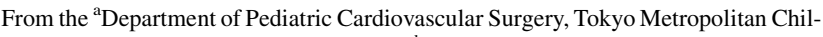
dren's Medical Center, Tokyo, Japan; ${ }^{\text {b}}$ Department of Pediatric Cardiovascular Surgery, Children's Medical Center, and ${ }^{\mathrm{c} D}$ Department of Cardiovascular Surgery, Kyoto Prefectural University of Medicine, Kamigyo-ku, Kyoto, Japan; and ${ }^{\mathrm{d} D e-}$ partment of Cardiovascular Surgery, Fukuoka Children's Hospital, Higashi-ku, Fukuoka, Japan.

Received for publication Nov 12, 2017; revisions received April 18, 2018; accepted for publication April 24, 2018; available ahead of print May 25, 2018.

Address for reprints: Yusuke Yamamoto, MD, Department of Pediatric Cardiovascular Surgery, Tokyo Metropolitan Children's Medical Center, 2-8-29 Musashidai, Fuchu-shi, Tokyo 184-8561, Japan (E-mail: acamais@gmail.com). $0022-5223 / \$ 36.00$

Copyright (C) 2018 by The American Association for Thoracic Surgery https://doi.org/10.1016/j.jtcvs.2018.04.107
}

durability. $^{1-3}$ In 2002, we developed the expanded polytetrafluoroethylene (ePTFE) conduit with fan-shaped leaflets and bulging sinuses for RVOT reconstruction and started clinical application and supply to other institutes in Japan. In the past 15 years, more than 1000 conduits have been used in 65 institutes in Japan, and follow-up studies have revealed good valve function and durability as described previously. ${ }^{4,5}$ The positive contribution of

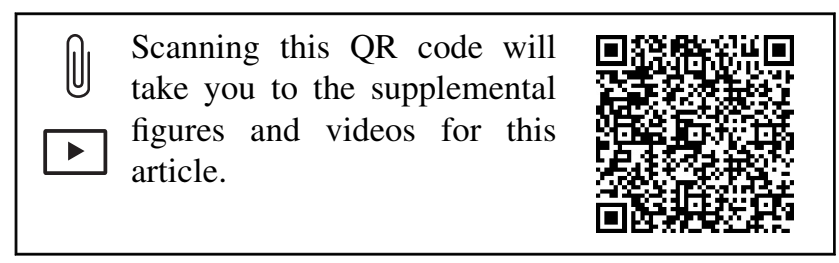




\section{Abbreviations and Acronyms}

$\mathrm{CI}=$ confidence interval

ePTFE $=$ expanded polytetrafluoroethylene

RVOT $=$ right ventricular outflow tract

bulging sinuses and fan-shaped leaflets to valve function has been demonstrated in an experimental study. ${ }^{6}$

We aimed for further improvement of the hemodynamic performance of the conduit, especially with regard to the material of the leaflet. Conventionally, the leaflet of this valved conduit was made from a $0.1 \mathrm{~mm}$-thick ePTFE sheet, and although this sheet is thinner than the native pulmonary valve (mean thickness $0.39 \pm 0.11 \mathrm{~mm}$ ), ${ }^{7}$ it might be slightly stiff as a leaflet material. We developed a new thin-type ePTFE sheet (mean thickness $0.040 \pm$ $0.008 \mathrm{~mm}$ ) by an original drawing process and manufactured a modified ePTFE conduit with this sheet as leaflet material.

The purpose of this study was to evaluate the clinical outcomes and hemodynamic performance of the modified conduit with thin-type leaflets in comparison with the conventional conduit with normal leaflets.

\section{MATERIALS AND METHODS \\ Patients}

The present study was a retrospective, observational, cohort study conducted at Kyoto Prefectural University of Medicine and Fukuoka Children's Hospital. The clinical application of the ePTFE tricuspid-valved conduit and the study protocol were approved by the ethics boards, and written informed consent was obtained from 1 or both parents of all patients.

A total of 149 consecutive patients who underwent definitive RVOT reconstruction using the ePTFE conduit at both institutes from January 2010 to December 2013 were included in this study. Since the clinical application of the modified conduit with thin-type leaflets was launched in June 2011, all patients received conventional conduits with normal leaflets from January 2010 to May 2011, and all patients received the modified conduits from October 2011 to December 2013. In the 4 months of the transitional period from June to September 2011, both types of conduit were used, with preference for the conventional one until its stocks ran out. No patient was excluded during this period for any reason.

\section{Expanded Polytetrafluoroethylene Tricuspid-Valved Conduit}

The ePTFE tricuspid-valved conduit is a handmade valve manufactured through 2 major processes: molding of bulging sinuses and sewing the leaflets to the inner surface of the conduit (Video 1). ${ }^{8}$ The diameter of the conduit ranges in 2-mm increments from 10 to $24 \mathrm{~mm}$ according to the size of the selected ePTFE graft (STRETCH Vascular Graft, WL Gore \& Associates, Inc, Flagstaff, Ariz); thus, it can be applied to a wide range of patients. Although conduits of 6 and $8 \mathrm{~mm}$ in diameter are also available, they are not tricuspid and therefore excluded from this study.

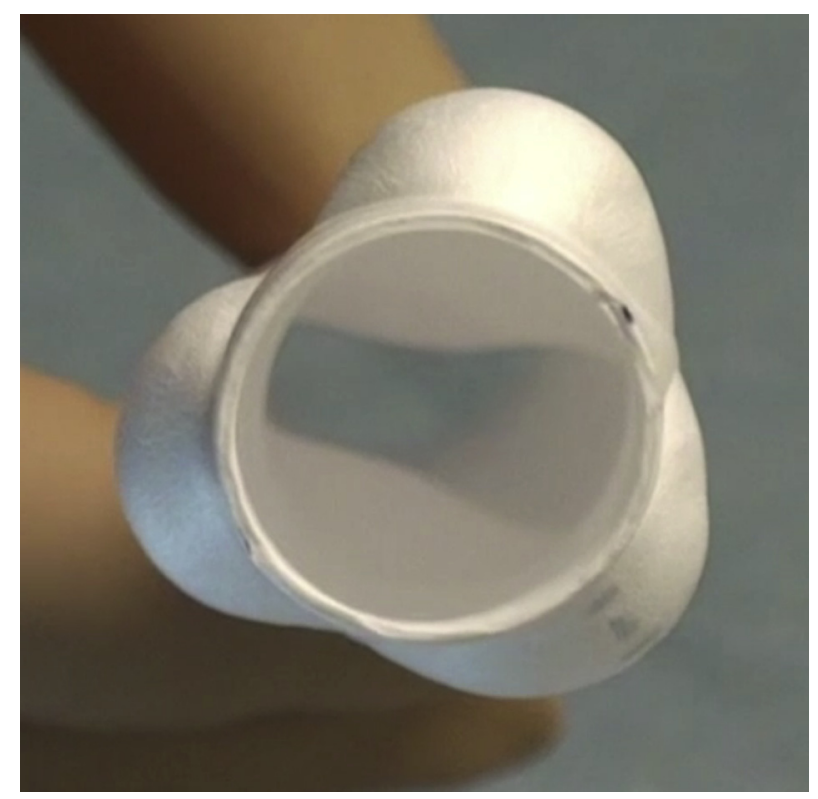

VIDEO 1. Manufacturing process of the ePTFE conduit with bulging sinuses and fan-shaped tricuspid valves. Video available at: https://www. jtcvs.org/article/S0022-5223(18)31247-9/fulltext.

The leaflet of the conventional conduit was made from a $0.1 \mathrm{~mm}$-thick ePTFE sheet (Preclude Pericardial Membrane, WL Gore \& Associates, Inc) cut in a fan-shape with a long free margin intended to accommodate a sufficient coaptation zone. On the other hand, the leaflet of the modified conduit was made of the thin-type ePTFE sheet with the same fan-shaped configuration (Figure E1 and Table E1). This thin-type sheet was made from a $0.1 \mathrm{~mm}$-thick ePTFE sheet by an original drawing process under heat application, with a mean thickness of $0.040 \pm 0.008 \mathrm{~mm}$. Tension testing of the 2 types of ePTFE sheet revealed that there was no significant difference in the ultimate tensile strength, that is, the maximum stress that a material can withstand while being stretched (Figure 1), and both values were far higher than that of the native pulmonary valve

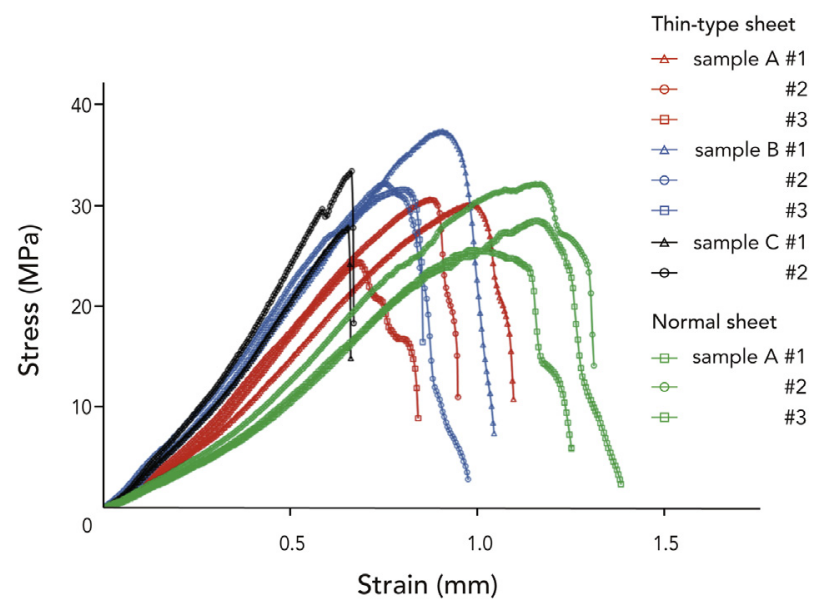

FIGURE 1. Stress-strain curve of the 2 types of ePTFE sheet. A total of 8 specimens obtained from 3 thin-type ePTFE sheets (samples A, B, and C) were examined. As a control, 3 specimens obtained from 1 normal ePTFE sheet were also examined. 

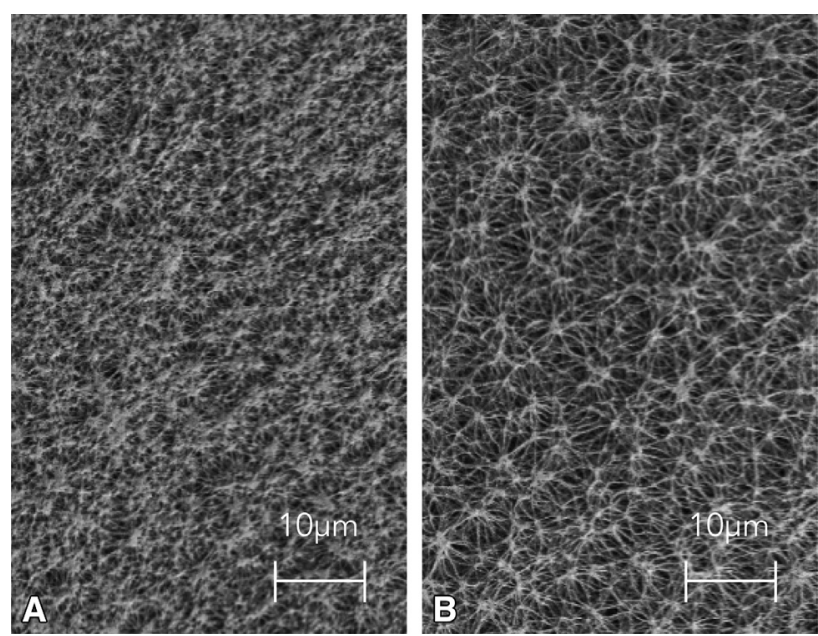

FIGURE 2. Scanning electron microscope images of normal and thintype ePTFE sheets $(1000 \times)$. A, Normal leaflet. B, Thin-type leaflet.

$(2.8 \pm 1.1 \mathrm{MPa}) .^{7}$ The breaking length, that is, the elongation length of the sheet just before it is broken by stretch was shorter for the thin-type sheet. No disruption of the ePTFE porous structure was detected on close inspection of the thin-type sheet with a scanning electron microscope, although there was a slight tendency for enlargement of micropore (Figure 2).

In the operative procedure, ${ }^{8}$ the conduit was implanted in the RVOT at the same location of the native pulmonary annulus, or, when anatomic implantation was difficult, at a location where compression by the sternum is avoidable. In addition, because of hemodynamic reasons, 1 of the 3 sinuses were necessarily placed at the greater curvature of the RVOT, whereas the midpoints of the other 2 sinuses were placed along the lesser curvature. Supplemental materials were not used in reconstruction of the continuity of the right ventricle to the pulmonary artery (Video 2). The size of the conduit was selected so that the $\mathrm{z}$-score of the conduit as the pulmonary valve to be approximately 1.4, although appropriate adjustments were necessary depending on the physical constitution and anatomic configuration of the heart. ${ }^{9}$ Postoperatively, anticoagulant or antiplatelet drugs were indicated only for patients receiving smaller-sized conduits.

\section{Data Collection}

Clinical data were collected by retrospective review of medical records. The follow-up period was defined as the interval between the surgical implantation of the conduit and the latest echocardiography.

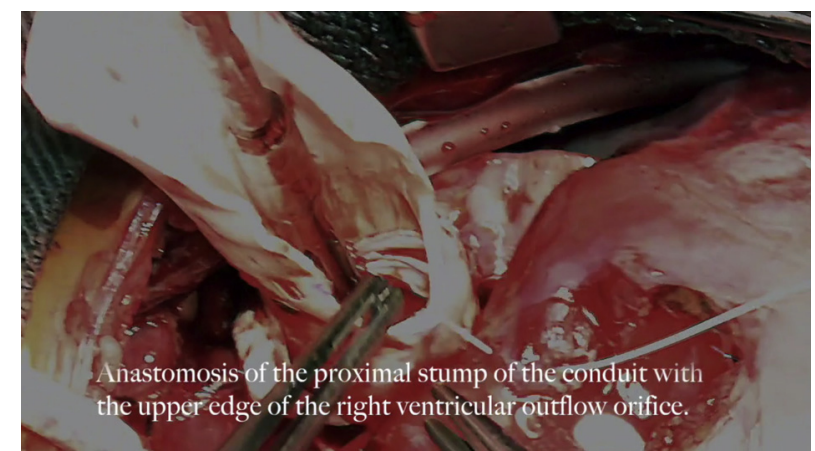

VIDEO 2. RVOT reconstructive surgery with the ePTFE valved conduit. Video available at: https://www.jtcvs.org/article/S0022-5223(18)31247-9/ fulltext.
The primary end points of the present study were overall survival, mortality rates in the early and late periods (ie, within and beyond 30 days after operation), and freedom from reintervention (conduit exchange, pulmonary artery reconstruction, catheter intervention, or a combination of them) with conduit-related reasons. The secondary end point was the hemodynamic performance of the conduit expressed by 2 parameters: peak pressure gradient across the conduit and grade of conduit insufficiency. The peak pressure gradient across the conduit was determined using the maximum velocity in the conduit measured by continuous Doppler echocardiography based on the commonly used guidelines. ${ }^{10}$ Conduit insufficiency was described using a 5 -grade relative estimate ( 0 , none; 1 , trivial; 2 , mild; 3 , moderate; and 4 , severe) according to the feature of the regurgitant jet flow described in echocardiography; this grading criteria was commonly used at both institutes.

The z-score of the conduit diameter as a pulmonary valve was calculated in accordance with a previously published nomogram. ${ }^{11}$ All hemodynamic data in this study were obtained only from the result of latest echocardiography.

\section{Statistical Analysis}

A comparative study was made between the 2 patient groups with different types of ePTFE tricuspid-valved conduits: patients who received the conventional conduit with normal leaflets (group N) and patients who received with the modified conduit with thin-type leaflets (group T). In relation to the peak pressure gradient and grade of conduit insufficiency, a subanalysis was performed after stratifying patients according to conduit diameter into small-sized category $(10,12$, and $14 \mathrm{~mm})$, middle-sized category $(16,18$, and $20 \mathrm{~mm}$ ), and large-sized category (22 and $24 \mathrm{~mm}$ ). Statistical comparisons of continuous variables (age at operation, body weight, follow-up period, and peak pressure gradient across the conduit) were performed using an independent $t$ test or the Mann-Whitney $U$ test according to the distribution of the data sets assessed by the Shapiro-Wilk test. For the independent $t$ tests, Student $t$ test and Welch's $t$ test were used as appropriate on the basis of the result of Levene's test performed beforehand. Patient survival and freedom from reintervention with conduit-related reasons were analyzed using the Kaplan-Meier method, and a comparison between the 2 groups was made using the log-rank test. Univariate Cox proportional hazard analysis was performed to elucidate the risk factors for reintervention with conduit-related reasons. Six parameters were included for this analysis: age at operation, body weight, diameter of the conduit, z-score of the conduit, nonanatomic implantation of the conduit, and use of the thin-type leaflet. Comparisons of ordinal variables such as the grade of conduit insufficiency were performed using the Mann-Whitney $U$ test. The proportion of male sex, the proportion of age less than 1 year, and the distribution of the operative procedure were compared using the chisquare test, whereas the distribution of the diameter of the implanted conduit was compared using the Kolmogorov-Smirnov test.

All values are shown as means \pm standard deviation or medians (interquartile range). All statistical analyses were conducted using IBM SPSS software (version 23, IBM Corp, New York, NY).

\section{RESULTS}

\section{Baseline Characteristics}

A total of 149 patients underwent definitive RVOT reconstruction with the ePTFE tricuspid-valved conduits from January 2010 to December 2013, and all of them were included in this study; 55 patients received the conventional conduit with normal leaflets (group N), and 94 patients received the modified conduit with thin-type leaflets (group $\mathrm{T})$. The number of patients stratified according to the size of conduit were as follows: 60 in the small-sized category (23 
TABLE 1. Patient characteristics

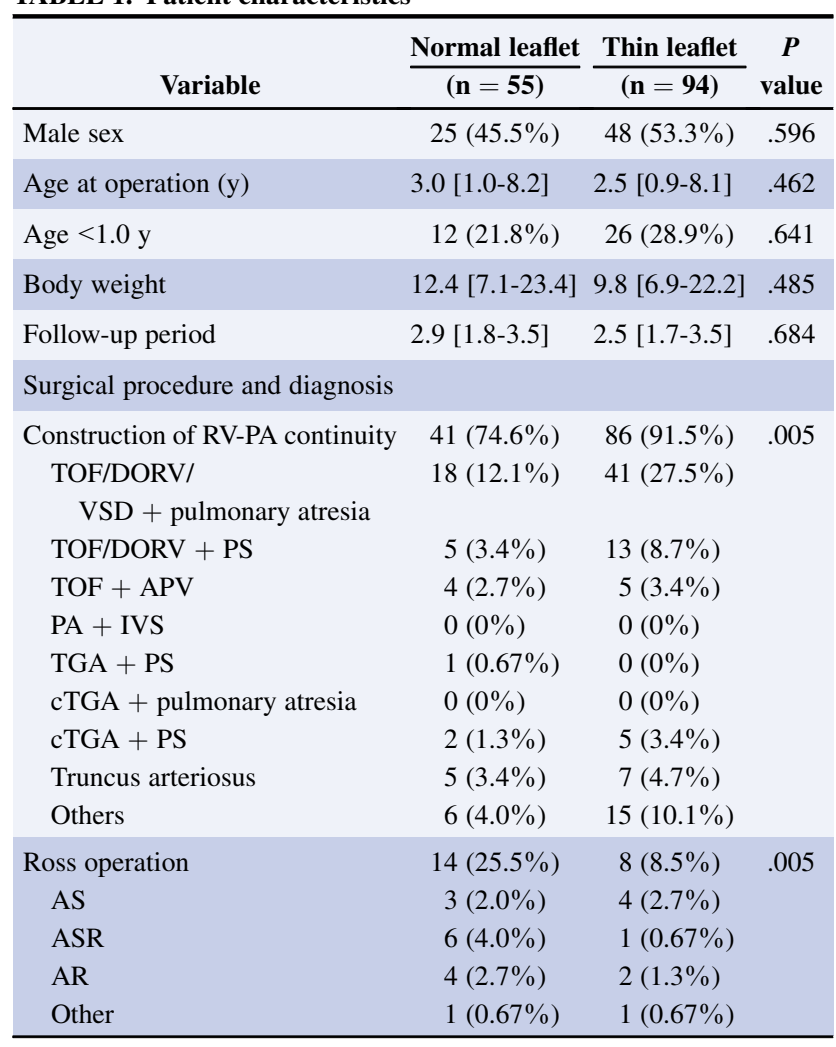

Data presented as number (\%) or median [interquartile range]. $R V$, Right ventricle $P A$, pulmonary atresia; $T O F$, tetralogy of Fallot; $D O R V$, double outlet right ventricle; $V S D$, ventricular septal defect; $P S$, pulmonary stenosis; $A P V$, absent pulmonary valve; $I V S$, intact ventricular septum; TGA, transposition of the great arteries; $c T G A$, corrected transposition of the great arteries; $A S$, aortic stenosis; $A S R$, aortic stenosis and regurgitation; $A R$, aortic regurgitation.

in group $\mathrm{N}$ vs 37 in group T), 62 in the middle-sized category ( 22 in group $\mathrm{N}$ vs 40 in group $\mathrm{T}$ ), and 27 in the large-sized category (10 in group $\mathrm{N}$ vs 17 in group $\mathrm{T}$ ). A follow-up study was performed with no patients dropping out from the survey. The demographic data of patients, including their anatomic diagnoses, are listed in Table 1. The median follow-up period was 2.9 years (1.8-3.3 years) in group $\mathrm{N}$ and 2.5 years (1.7-3.5 years) in group $\mathrm{T}$ $(P=.684)$. Although the patient numbers differed because of the discrepancy of the target period, other baseline characteristics were well balanced, with no significant differences. With regard to the distribution of the operative procedure, the proportion of patients who underwent the Ross procedure was significantly larger in group $\mathrm{N}$ ( $25.5 \%$ in group $\mathrm{N}$ vs $8.5 \%$ in group $\mathrm{T}, P=.005)$. Further investigation about this proportion in the categories stratified according to conduit size revealed $4.4 \%$ versus $0.0 \%$ $(P=.201)$ in the small-sized category, $30.4 \%$ versus $2.5 \%(P=.001)$ in the middle-sized category, and $60.0 \%$ versus $41.2 \%(P=.345)$ in the large-sized category. There was no significant difference $(P=.895)$ in the distribution of diameter size (millimeters) of the implanted conduit

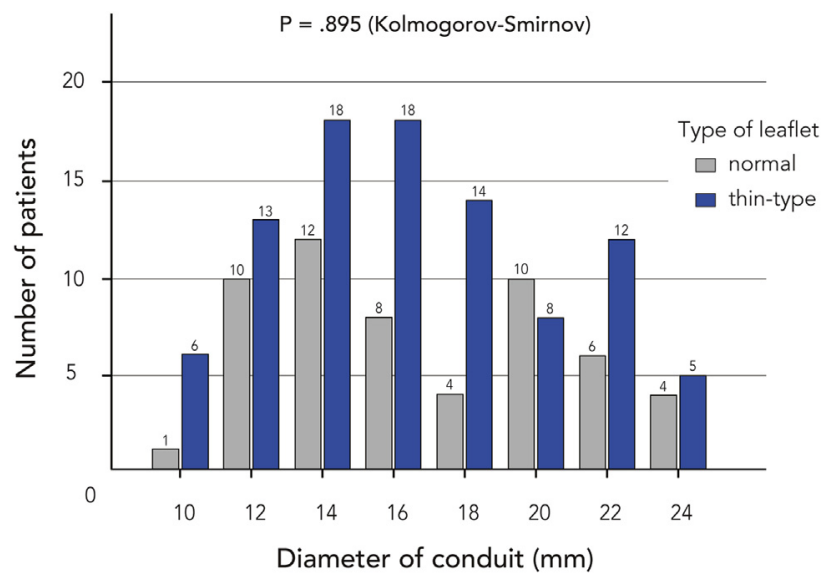

FIGURE 3. Distribution of conduit sizes in each group.

(Figures 3 and E2). The median z-score of the implanted conduit was $1.45(0.45-2.00)$ for group $\mathrm{N}$ and $1.45(0.70-$ 2.20) for group $\mathrm{T}(P=.217)$.

\section{Mortality}

There were 2 deaths ( 1 in each group) within 30 days after conduit implantation, with 1 patient dying of sepsis 6 days after surgery and 1 patient dying of severe left ventricular dysfunction 17 days after surgery. Early mortality rates were $1.8 \%$ for group $\mathrm{N}$ and $1.1 \%$ for group $\mathrm{T}$. There were 3 deaths (all in group $\mathrm{T}$ ) beyond 30 days after conduit implantation, with 1 patient dying of sepsis, 1 patient dying of respiratory failure due to bronchial stenosis, and 1 patient dying of viral encephalitis. The late mortality rates were $0.0 \%$ for group $\mathrm{N}$ and $3.2 \%$ for group $\mathrm{T}$. The overall 3 -year survival was $98.2 \%$ (95\% confidence interval [CI], 94.7-100) for group $\mathrm{N}$ and $95.6 \%$ (95\% CI, 91.5-99.7) for group T $(P=.438)$ (Figure $4, A)$. Valve-related death was not observed in either group.

\section{Reintervention for the Conduit}

A total of 8 patients required conduit replacement, and catheter intervention was not required in any of the patients. The indications for conduit replacement were as follows: relative stenosis due to somatic growth ( 1 in group $\mathrm{N}$ and 2 in group T), incidental conduit exchange for larger sized conduit concomitant with other procedures ( 1 in group $\mathrm{N}$ and 3 in group $\mathrm{T}$ ), and conduit infection subsequent to gastrostomy ( 1 in group $\mathrm{N}$ and none in group $\mathrm{T}$ ). Conduit replacement due to conduit failure was not undertaken in either group. Freedom from reintervention with conduit-related reasons at 3-year follow-up was $94.7 \%$ (95\% CI, 87.4-100) for group $\mathrm{N}$ versus $97.9 \%(95 \% \mathrm{CI}, 93.8-100)$ for group $\mathrm{T}$ $(P=.954)$ (Figure $4, B)$. In univariate Cox proportional hazard analysis, no variable was identified as a risk factor for reintervention with conduit-related reasons (Table E2). 

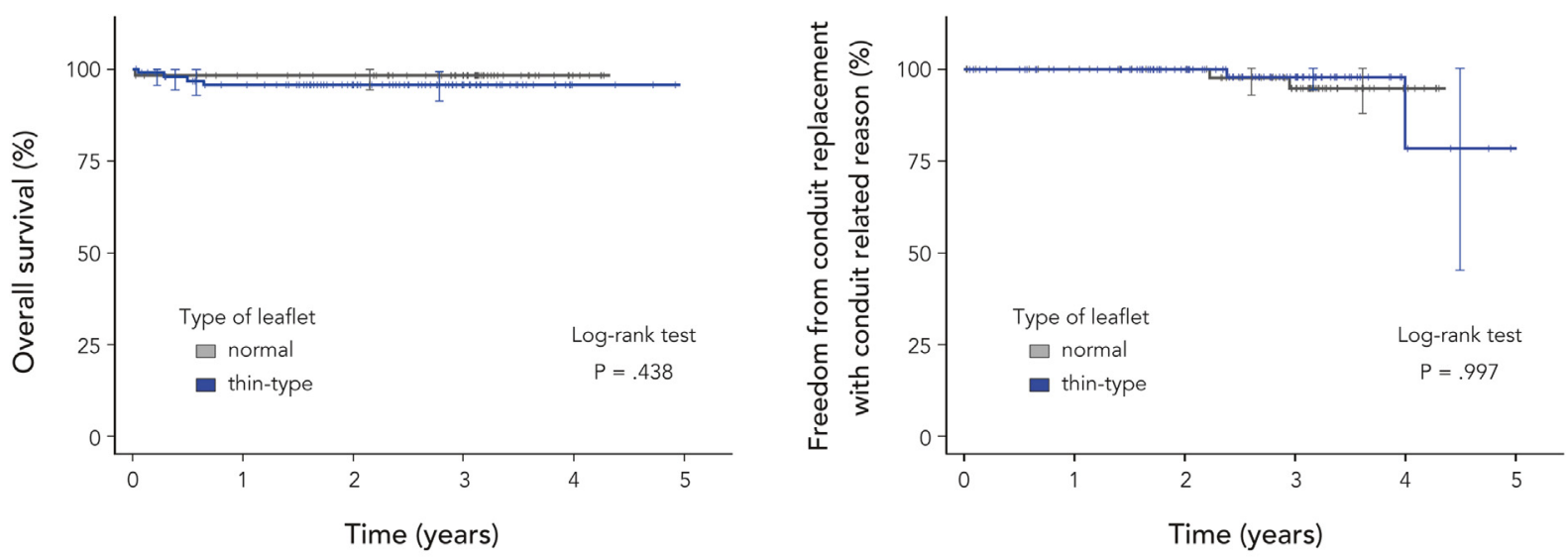

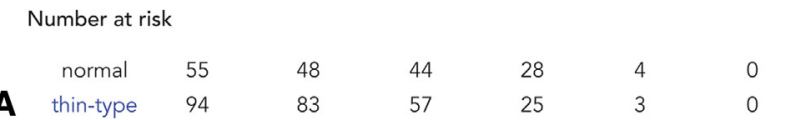

\begin{tabular}{ccccccc}
\multicolumn{2}{c}{ Number at risk } \\
B $\begin{array}{c}\text { normal } \\
\text { thin-type }\end{array}$ & 55 & 48 & 44 & 27 & 5 & 0 \\
& 94 & 83 & 57 & 25 & 3 & 0
\end{tabular}

FIGURE 4. Kaplan-Meier curves of overall survival (A) and freedom from reintervention (B) with conduit-related reasons.

\section{Hemodynamic Performance of the Conduit}

Two patients who died within 30 days postoperatively were excluded because of lacking precise echocardiography, and a total of 147 patients ( 54 in group $\mathrm{N}$ vs 93 in group T) were included in the analysis of hemodynamic performance of the conduit. Of these patients, 59 were in the small-sized category ( 22 in group $\mathrm{N}$ vs 37 in group T), 61 were in the middle-sized category ( 22 in group $\mathrm{N}$ vs 39 in group T), and 27 were in the large-sized category (10 in group $\mathrm{N}$ vs 17 in group T). None of the patients experienced hemodynamic deterioration due to conduit malfunction.

The peak pressure gradient across the conduit tended to be low in group $\mathrm{T}(22.6 \pm 15.6 \mathrm{~mm} \mathrm{Hg}$ in group $\mathrm{N}$ vs $18.2 \pm 11.5 \mathrm{~mm} \mathrm{Hg}$ in group T, $P=.161)$. In subanalysis after stratification according to conduit size, group $\mathrm{T}$ showed a significantly lower pressure gradient $(30.2 \pm 16.5$ vs $20.4 \pm 10.7 \mathrm{~mm} \mathrm{Hg}, P=.034)$ in the small-sized category (Figure 5). In the comparison of conduit insufficiency, there was no significant difference or obvious tendency toward a difference in the total cohort $(P=.243)$. In the subanalysis stratified according to conduit size, group $\mathrm{T}$ showed significantly worse grade of conduit insufficiency $(P=.014)$ in the large-sized category (Figure 6). Fixation of the leaflet in open or closed position was not observed in this study, and all leaflets were kept in motion.

\section{DISCUSSION}

Although various materials are available as prosthetic valves in RVOT reconstructive surgery, none of them are satisfactory in terms of durability and availability. Because of size restrictions, options for pediatric patients are mostly limited to homograft or bovine jugular vein graft in European and American countries; however, deficient durability due primarily to immunologic rejection arises frequently, particularly when implanted into young patients. ${ }^{12,13}$ In Japan, where both of them are generally unavailable because of legal problems and regional reasons, handmade valves with ePTFE material are most commonly used. ePTFE is thought to be an ideal material with low antigenicity and antithrombogenic characteristics with endothelialization achieved after implantation. ${ }^{14}$ In addition, the ePTFE tricuspid-valved conduit has 2 structural features: fan-shaped leaflets with a broad coaptation zone and bulging sinuses imitating the sinus of Valsalva of the native aortic root. According to

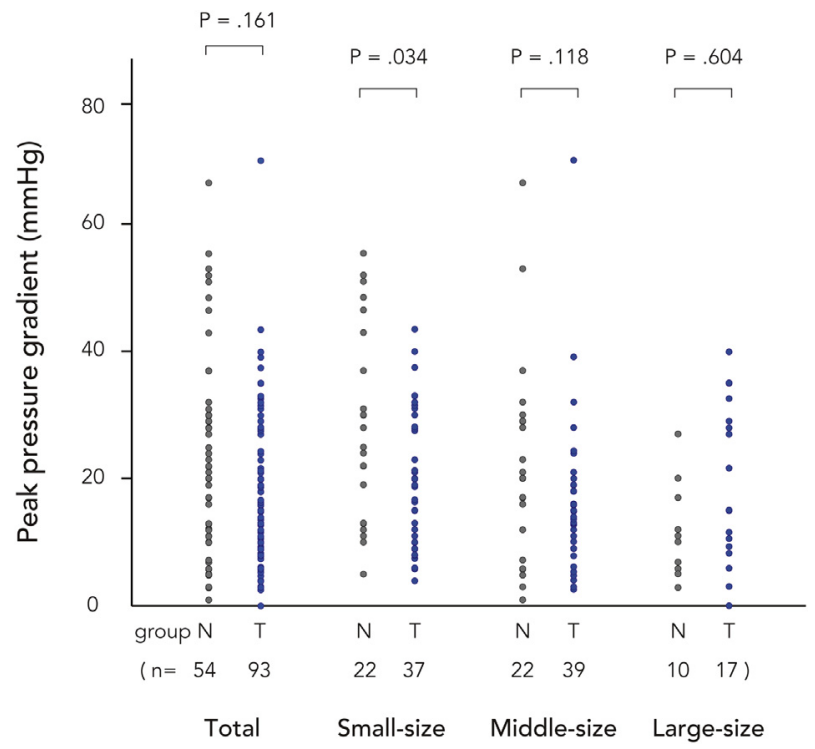

FIGURE 5. Peak pressure gradient across the conduit in the latest echocardiography. 


\section{Total cohort}

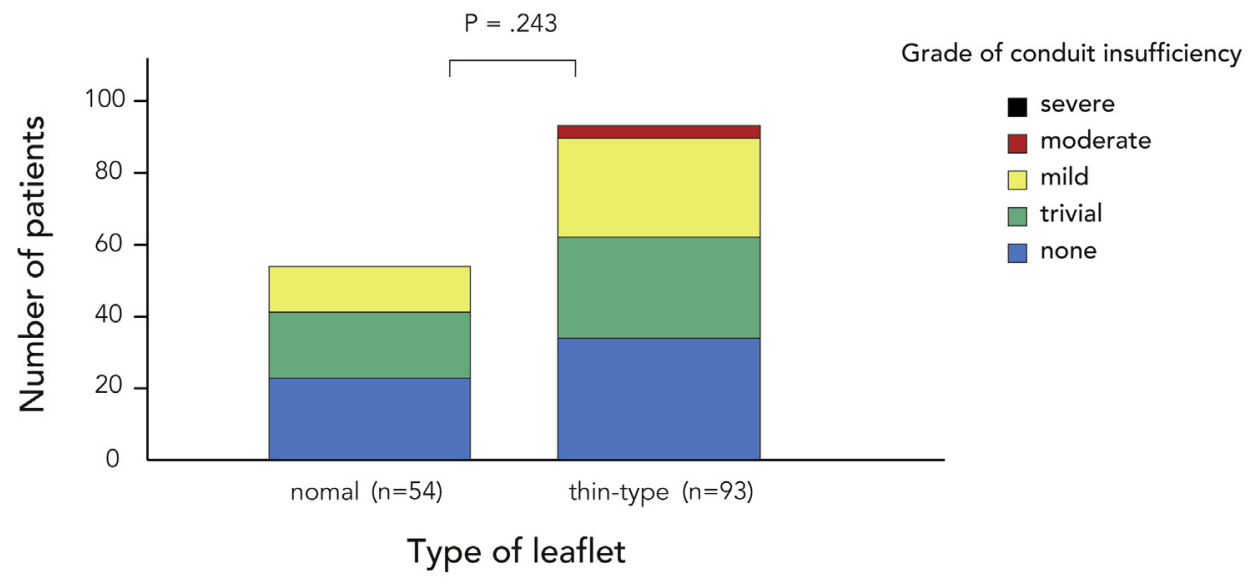

Small size

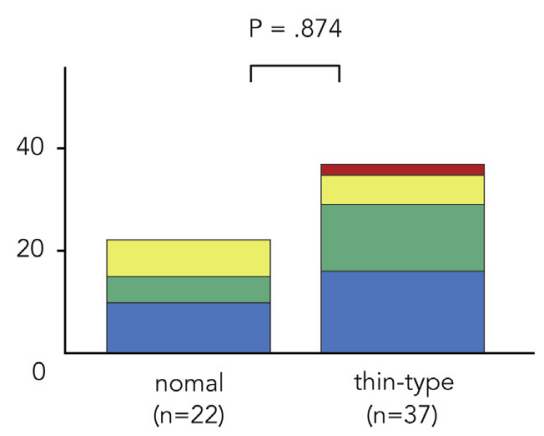

Middle size

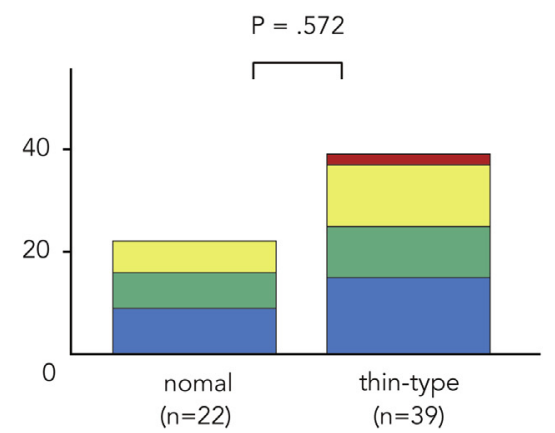

Large size

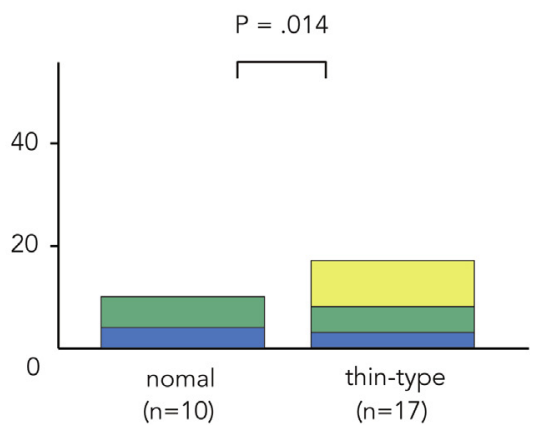

FIGURE 6. Grade of conduit insufficiency in the latest echocardiography.

experimental studies, the fan-shaped leaflets produce enlargement of valve opening area and reduction of regurgitant flow, transvalvular pressure gradient, and energy loss through the valve. ${ }^{6}$ Experimental studies also revealed that the bulging sinuses form a vortex flow within themselves, which is considered to produce rapid and smooth closure of the valve and to reduce mechanical stress on the leaflets ${ }^{15}$ and laminar flow at the center of the valve. ${ }^{6}$ Multicenter studies in Japan revealed excellent midterm results comparable to or even better than those of other prosthetic materials. ${ }^{4,5}$

In an attempt to improve the hemodynamic performance of the valve, we developed a new thin-type ePTFE sheet and manufactured a modified tricuspid-valved conduit with this sheet as leaflet material. Its validity and safety for clinical application were ensured by enough tensile strength and the preserved porous structure of the ePTFE material confirmed by several material tests, although the impact of the shorter breaking length, indicating less toughness, on chronologic degeneration of valve function still needs to be observed. The purpose of this study was to evaluate the clinical outcomes and hemodynamic performance of the modified conduit with thin-type leaflets in comparison with the conventional conduit with normal leaflets.

In this retrospective, observational, cohort study, the allocation of the 2 types of ePTFE conduit was decided only by the date of implantation except for the 4 months of transitional period, and the 2 groups were thought to be sufficiently comparable without any statistical corrections. Although the baseline characteristics of the patients in the 2 groups did not differ significantly, the proportion of patients who underwent the Ross operation was significantly greater in group N. Because the nonanatomic implantation of the conduit in RVOT reconstruction is known as an independent risk factor for conduit dysfunction, ${ }^{16,17}$ this disproportion might work against group T. Except for this problem, all other data supported the statistical equivalency of the 2 groups; therefore, comparison between these 2 groups was thought to be appropriate.

The overall survival, early and late mortality rates, and freedom from reintervention with conduit-related reasons were all similar between the 2 groups, with no conduitrelated deaths. There were no reinterventions to the conduit 


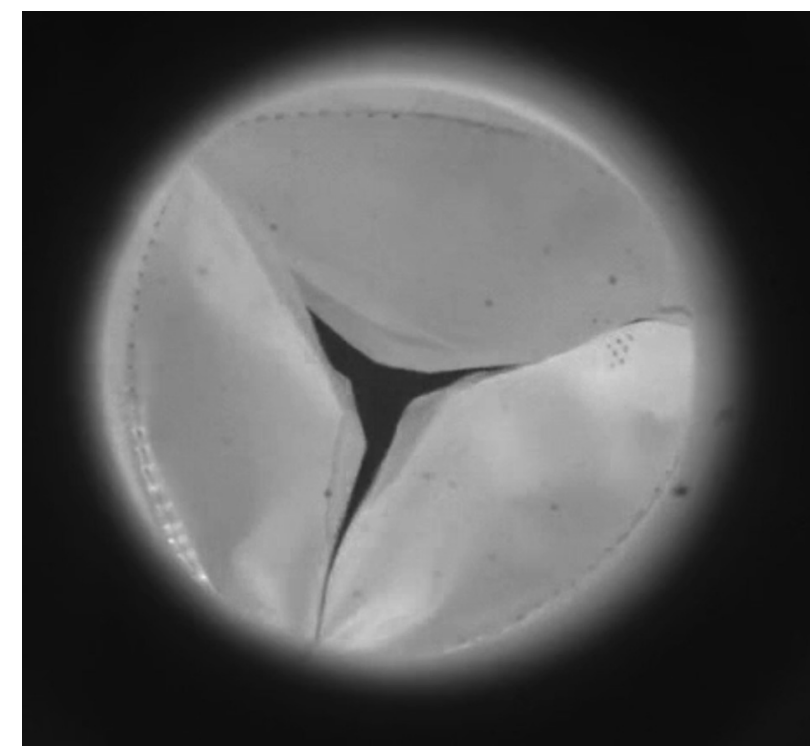

VIDEO 3. Movements of the thin-type leaflets captured by a high-speed video camera at 300 frames per second. Video available at: https://www. jtcvs.org/article/S0022-5223(18)31247-9/fulltext.

due to degeneration of the conduit itself, and freedom from reintervention was similar between the 2 groups. Degradation of leaflets, such as disruption or calcification, was not observed, and all leaflets were in motion. From these results, we concluded that the midterm outcomes of the modified conduits were equivalent to those of conventional conduits, without any obvious benefits or disadvantages.

The hemodynamic performance of the ePTFE conduit was estimated using 2 parameters: peak pressure gradient across the conduit and grade of conduit insufficiency. In the comparison of peak pressure gradient, the modified conduit with the thin-type leaflets tended to show a lower pressure gradient, and this tendency became significant especially within the small-sized category. As is evident from the image of the valve motion captured by a highspeed video camera (Video 3), the thin-type leaflets opens more quickly and widely than the normal leaflets, and this flexibility likely explains the reduction of the pressure gradient. Moreover, it was expected that the relative flexibility of the thin-type leaflets would become more obvious in small-sized category, and therefore reduction of the pressure gradient becomes more prominent.

With respect to conduit insufficiency, there was no obvious advantage of the modified conduit over the conventional conduit, and especially for the large-sized conduits, the thin-type leaflets worsened the grade of conduit insufficiency. A possible speculation about this result is that the thin-type leaflet is too flexible to maintain the valve configuration under diastolic pressure in large-sized conduits, although the detailed mechanism of this result requires further investigation, such as observation of leaflet movement by a high-speed video camera or a computational fluid dynamic study. Difference of patient characteristics between the 2 groups did not supposed to affect this result because the proportion of patients who underwent the Ross operation was not significantly different within the large-sized category.

In the present study, primary end points, that is, clinical outcomes such as deaths and reinterventions, did not differ between the 2 groups with extremely small numbers of events. Therefore, the secondary end point, that is, the hemodynamic performance of the conduits, was used to assess the feasibility of the thin-type leaflet for modification of the ePTFE conduit. Because the function of the ePTFE conduit is generally maintained for more than 5 years, ${ }^{6}$ which is longer than the follow-up period of this study, the results of the present study should be explained by the structural properties of each conduit rather than by the difference of degenerative changes. As for the small-sized conduits that were used mainly for small children (Figure E2), relative stenosis of the conduit due to somatic growth is almost inevitable within a few years after implantation, and subsequent conduit exchange is likely in the future. Therefore, the longterm durability is not necessarily of great importance, and it would be reasonable to regard the thin-type leaflet as feasible material for small-sized conduit based on the superiority of the hemodynamic performance. In contrast, the proven inferiority of the thin-type leaflet invalidates its use for the large-sized conduits.

It is indicated that the thin-type leaflet is suitable for the small-sized conduits, but not for large-sized conduits. With respect to middle-sized conduits, the appropriate type of leaflet material is a subject for future analysis.

\section{Study Limitations}

Because hemodynamic performance of the ePTFE tricuspid-valved conduit is generally kept over 5 years or more, ${ }^{4,5}$ the observation period in the current study was too short to examine the differences of chronologic changes in valve function in each group, and further observation is necessary. In addition, although histopathologic examination of the explanted conduit is essential to assess degeneration of the thin-type leaflets, especially in relation to the changed microstructure through the drawing process, we have only a few specimens of explanted conduit to date, and further accumulation of specimens are needed (Figure E3).

\section{CONCLUSIONS}

From the present study, we conclude that the thin-type ePTFE sheet is safe and reliable as leaflet material at least over midterm follow-up, and that it is reasonable to apply it for the small-sized conduits $(10,12$, and $14 \mathrm{~mm}$ in diameter) but not for the large-sized conduits ( 22 and $24 \mathrm{~mm}$ in diameter). Further accumulation of clinical data and 
analysis of explanted specimens are necessary to determine the appropriate sheet type for the middle-sized conduits (16, 18 , and $20 \mathrm{~mm}$ in diameter) and to estimate the durability of the thin-type leaflet.

\section{Conflict of Interest Statement}

Authors have nothing to disclose with regard to commercial support.

\section{References}

1. Ruzmetov M, Shah JJ, Geiss DM, Fortuna RA. Decellularized versus standard cryopreserved valve allografts for right ventricular outflow tract reconstruction: a single-institution comparison. J Thorac Cardiovasc Surg. 2012;143:543-9.

2. Mery CM, Guzman-Pruneda FA, De Leon LE, Zhan W, Terwelp MD, Bocchini CE, et al. Risk factors for development of endocarditis and reintervention in patients undergoing right ventricle to pulmonary artery valved conduit placement. J Thorac Cardiovasc Surg. 2016;151:432-9.

3. Nomoto R, Sleeper LA, Borisuk MJ, Bergerson L, Pigula FA, Emani S, et al. Outcome and performance of bioprosthetic pulmonary valve replacement in patients with congenital heart disease. J Thorac Cardiovasc Surg. 2016;152: $1333-42$.

4. Miyazaki T, Yamagishi M, Maeda Y, Yamamoto Y, Taniguchi S, Sasaki Y, et al. Expanded polytetrafluoroethylene conduits and patches with bulging sinuses and fan-shaped valves in right ventricular outflow tract reconstruction: multicenter study in Japan. J Thorac Cardiovasc Surg. 2011;142:1122-9.

5. Miyazaki T, Yamagishi M, Maeda Y, Taniguchi S, Fujita S, Hongu H, et al. Longterm outcomes of expanded polytetrafluoroethylene conduits with bulging sinuses and a fan-shaped valve in right ventricular outflow tract reconstruction. $J$ Thorac Cardiovasc Surg. February 9, 2018 [Epub ahead of print].

6. Suzuki I, Shiraishi Y, Yabe S, Tsuboko Y, Sugai TK, Matsue K, et al. Engineering analysis of the effects of bulging sinuses in a newly designed pediatric pulmonary heart valve on hemodynamic function. J Artif Organs. 2012;15:49-56.

7. Stradins P, Lacis R, Ozolanta I, Purina B, Ose V, Feldmane L, et al. Comparison of biomechanical and structural properties between human aortic and pulmonary valve. Eur J Cardiothorac Surg. 2004;26:634-9.
8. Yamagishi M. Right ventricular outflow reconstruction using a polytetrafluoroethylene conduit with bulging sinuses and tricuspid fan-shaped polytetrafluoroethylene valve. Oper Tech Thorac Cardiovasc Surg. 2017;21:211-29.

9. Yamashita E, Yamagishi M, Miyazaki T, Maeda Y, Yamamoto Y, Kato N, et al. Smaller-sized expanded polytetrafluoroethylene conduits with a fan-shaped valve and bulging sinuses for right ventricular outflow tract reconstruction. Ann Thorac Surg. 2016;102:1336-44.

10. Baumgartner H, Hung J, Bermejo J, Chambers JB, Evangelista A, Griffin BP, et al. Echocardiographic assessment of valve stenosis: EAE/ASE recommendations for clinical practice. J Am Soc Echocardiogr. 2009;10:1-25.

11. Kirklin JW, Blackstone EH, Jonas RA, Kouchoukos NT. Chapter 1. Anatomy, dimensions, and terminology. In: Kirklin JW, Barratt-Boyes BG, eds. Cardiac Surgery. 3rd ed. Edinburgh: Churchill Livingstone; 2004:50.

12. Schoenhoff FS, Loup O, Gahl B, Banz Y, Pavlovic M, Pfammatter JP, et al. The Contegra bovine jugular vein graft versus the Shelhigh pulmonic porcine graft for reconstruction of the right ventricular outflow tract: a comparative study. $J$ Thorac Cardiovasc Surg. 2011;141:654-61.

13. Vogt PR, Stallmach T, Niederhauser U, Schneider J, Zund G, Lachat M, et al. Explanted cryopreserved allografts: a morphological and immunohistochemical comparison between arterial allografts and allograft heart valves from infants and adults. Eur J Cardiothorac Surg. 1999;15: 639-44.

14. Yamamoto Y, Yamagishi M, Miyazaki T. Current status of right ventricular outflow tract reconstruction: complete translation of a review article originally published in Kyobu Geka. 2014;67:65-77. Gen Thorac Cardiovasc Surg. 2014; 63:131-41.

15. Katayama S, Umetani N, Sugiura S, Hisada T. The sinus of Valsalva relieves abnormal stress on aortic valve leaflets by facilitating smooth closure. $J$ Thorac Cardiovasc Surg. 2008;136:1528-35.

16. Urso S, Rega F, Meuris B, Gewillig M, Eyskens B, Daenen W, et al. The Contegra conduit in the right ventricular outflow tract is an independent risk factor for graft replacement. Eur J Cardiothorac Surg. 2011;40:603-9.

17. Emani SM. Options for prosthetic pulmonary valve replacement. Semin Thorac Cardiovasc Surg Pediatr Card Surg Annu. 2012;15:34-7.

Key Words: right ventricular outflow tract reconstruction, ePTFE valved conduit, fan-shaped valve, bulging sinus, thin-type leaflet 


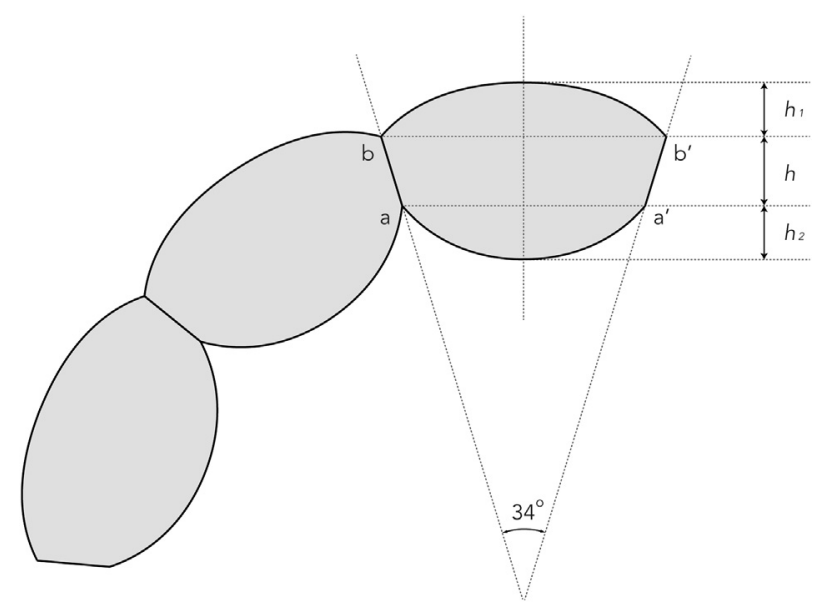

FIGURE E1. The basic shape of the ePTFE fan-shaped tricuspid leaflet. Values of the 4 essential dimensions $\left(\mathrm{a}-\mathrm{a}^{\prime}, \mathrm{h}_{1}, \mathrm{~h}\right.$, and $\left.\mathrm{h}_{2}\right)$ are shown in Table E2. The length of the lower edge of the leaflet $\left(a-a^{\prime}\right)$ is equal to the conduit diameter $\times 3.14 / 3$.

Normal leaflet

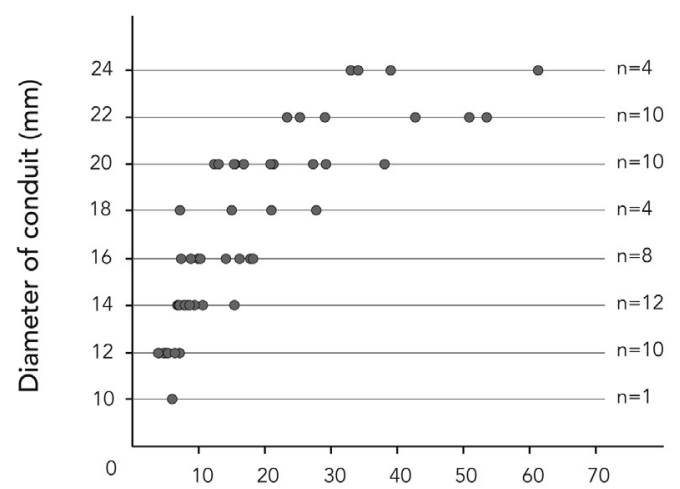

Thin leaflet

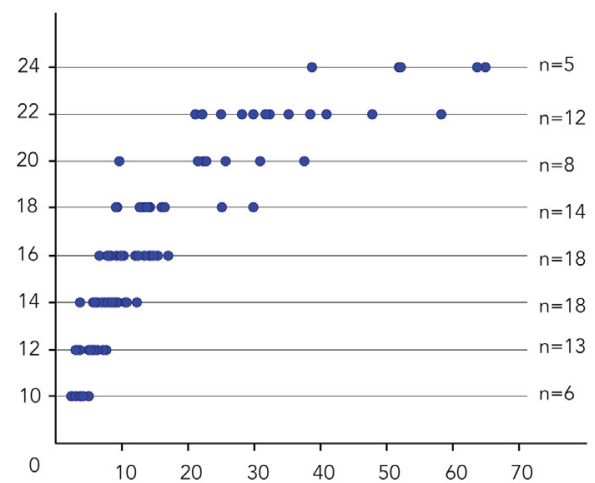

Body weight of patient $(\mathrm{kg})$

FIGURE E2. Distribution of conduit sizes in each group in accordance with patient's body weight. 
(a)

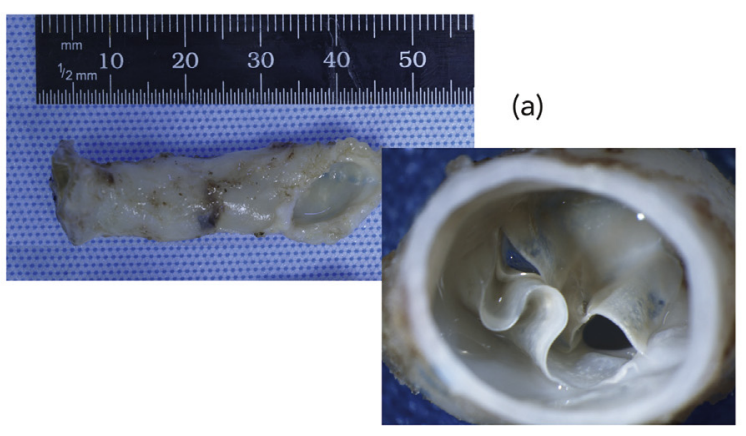

A

(b)

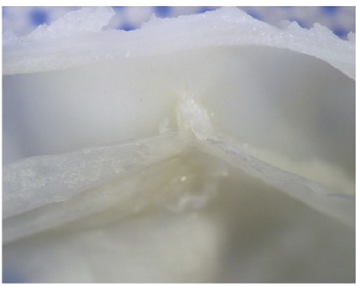

(b)

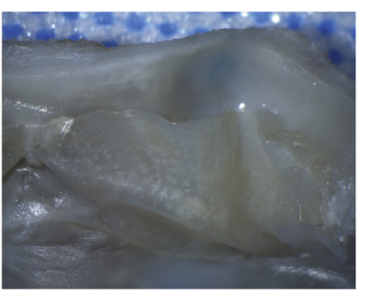

(c)

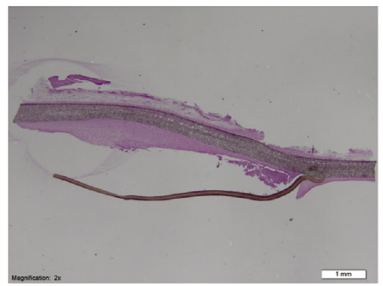

(c)

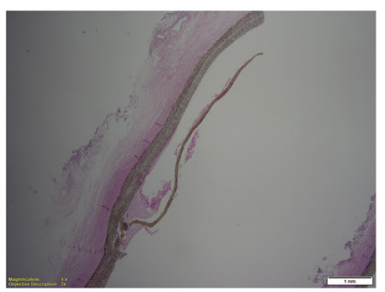

FIGURE E3. Explanted specimen of the ePTFE conduit. A, Conduit ( $8 \mathrm{~mm}$ in diameter, bicuspid) with normal leaflet implanted for 14 months. B, Conduit (10 mm in diameter, tricuspid) with thin-type leaflet implanted for 17 months. (a), macroscopic view of external appearance. (b), macroscopic view of leaflet. (c), microscopic view of tissue section with hematoxylin and eosin stain (magnification $2 \times$ ).

TABLE E1. Dimensions of the fan-shaped leaflet according to the size of the conduit

\begin{tabular}{lcccccccccc}
\hline Conduit size (mm) & $\mathbf{6}$ (monocusp) & $\mathbf{8}$ (bicusp) & $\mathbf{1 0}$ & $\mathbf{1 2}$ & $\mathbf{1 4}$ & $\mathbf{1 6}$ & $\mathbf{1 8}$ & $\mathbf{2 0}$ & $\mathbf{2 2}$ & $\mathbf{2 4}$ \\
\hline $\mathrm{a}^{-} \mathrm{a}^{\prime}(\mathrm{mm})$ & 9.5 & 11 & 10.5 & 12.5 & 14.5 & 17 & 19 & 21 & 23 & 25 \\
$\mathrm{~h} 1(\mathrm{~mm})$ & 2 & 2 & 2.5 & 2.5 & 3 & 3.5 & 4 & 4.5 & 5 & 5 \\
$\mathrm{~h}(\mathrm{~mm})$ & 3 & 3 & 3.5 & 4 & 4.5 & 4.5 & 5 & 5.5 & 6 & 6.5 \\
$\mathrm{~h} 2(\mathrm{~mm})$ & 2 & 2 & 2.5 & 3 & 4 & 4 & 4.5 & 5 & 5.5 & 6 \\
\hline
\end{tabular}

Four dimensions $\left(\mathrm{a}-\mathrm{a}^{\prime}, \mathrm{h} 1, \mathrm{~h}\right.$, and $\left.\mathrm{h} 2\right)$ of the fan-shaped leaflet are illustrated in Figure E1. 
TABLE E2. Univariate Cox regression analysis for freedom from reintervention

\begin{tabular}{lcc}
\hline \multicolumn{1}{c}{ Variable } & HR $(\mathbf{9 5} \% \mathbf{C I})$ & $\boldsymbol{P}$ value \\
\hline Age at operation & $0.58(0.27-1.25)$ & .164 \\
Body weight & $0.77(0.56-1.06)$ & .107 \\
Diameter of conduit & $0.53(0.30-0.95)$ & .320 \\
Z-score of conduit & $0.63(0.22-1.81)$ & .388 \\
Use of thin-type leaflet & $1.00(0.14-7.18)$ & .997 \\
\hline$H R$, Hazard ratio; $C I$, confidence interval.
\end{tabular}

